\title{
Pharmacological constriction of the lower oesophageal sphincter: a simple method of arresting variceal haemorrhage
}

\author{
S W HOSKING, W DOSS, H EL-ZEINY, P ROBINSON, M S BARSOUM, \\ AND A G JOHNSON \\ From the Departments of Surgery, Royal Hallamshire Hospital, Sheffield and Kasr El Aini Hospital, Cairo, \\ Egypt
}

SUMmaRY The effect of pharmacological constriction of the lower oesophageal sphincter (LOS) on oesophageal varices was investigated in an experimental study followed by a controlled clinical trial. In the experimental study intravariceal pressure was measured just above the LOS in 11 patients before and after constricting the LOS by intravenous pentagastrin. Intravariceal pressure fell from a mean of 23 (range 12-36) $\mathrm{mmHg}$ to 4 (range $0-7) \mathrm{mmHg}(\mathrm{p}<0.001)$. This marked pressure drop indicated the considerable compression of varices that occurred within the LOS. A prospective controlled clinical trial examined whether LOS constriction (effected by the longer acting metoclopramide) would compress varices sufficiently to arrest active variceal bleeding originating from the lowest $2 \mathrm{~cm}$ oesophagus - the area encircled by the LOS. Of 11 patients who received metoclopramide, 10 stopped bleeding compared with four of the 11 who received placebo $(p<0 \cdot 01)$. Pharmacological constriction of the LOS appears to offer a new and effective approach for arresting active bleeding from oesophageal varices.

Bleeding from oesophageal varices is a serious complication of portal hypertension. The mortality of the first bleed, even when actively treated in specialised units is approximately $30 \%,,^{12}$ and may be considerably more in other centres. One of the most demanding aspects of treatment is the arrest of active variceal bleeding. The most effective methods are seldom available outside specialised centres, and even then have an appreciable morbidity. We have examined a new approach to this difficult clinical problem.

Oesophageal varices usually bleed from their lowest $2 \mathrm{~cm}^{3}$ and this area is encircled by the lower oesophageal spincter (LOS). In 1978 Miskowiak $^{4}$ suggested that constricting the LOS with drugs might affect blood flow in oesophageal varices. Using portography, he and colleagues showed that drugs which constrict the LOS caused a reduction or abolition of submucosal variceal blood flow whilst

Address for correspondence: Professor A G Johnson. University Surgical Unit, Royal Hallamshire Hospital, Sheffield S102JF.

Received for publication 7 March 1988. flow through paraoesophageal veins was not affected. "This was confirmed by Lunderquist et al."

The present study was designed in two parts. In the first part, an experimental study examined whether pharmacological LOS constriction, by compressing varices within the LOS zone, would reduce intravariceal pressures recorded cephalad to the LOS. Based on encouraging results obtained in this study, a controlled trial was then performed to examine whether LOS constriction, effected by metoclopramide, would compress oesophageal varices sufficiently to arrest active bleeding.

\section{Methods}

PATIENTS

EXPERIMENTAL STUDY (CARRIED OUT IN SHEFFIELD)

Eleven patients who had received no previous treatment for their oesophageal varices were studied just before sclerotherapy. 
Two cannulae were used to record simultaneously intraoesophageal and intravariceal pressures (Fig. 1). The single lumen intraoesophageal cannula had an external diameter of $2 \mathrm{~mm}$ and three side ports at $120^{\circ}$ intervals in the terminal $5 \mathrm{~mm}$ as well as an open end. This and a variceal injection cannula (used to record intravariceal pressures), were perfused with $5 \%$ dextrose at $0.05 \mathrm{ml} /$ minute through flow regulators (CSF Intraflow II, Abbott Laboratories). The perfused cannulae were connected to transducers (S9B, Gaeltec) and a chart recorder (model 8088, Gould).

After topical pharyngeal anaesthesia and light sedation (2.5-10 mg Diazemuls), the intraoesophageal cannula was passed. An Olympus Q-10 endoscope was then introduced so that its tip lay $6 \mathrm{~cm}$ above the oesophagogastric junction. The contracted LOS could be seen $1 \mathrm{~cm}$ distal to the site of intended variceal puncture. The intraoesophageal cannula tip was then positioned at the same level. After passing the injection cannula via the endoscope, one varix was punctured with the needle and readings were obtained at rest for two minutes. Pentagastrin $5 \mu \mathrm{g} / \mathrm{kg}$ was then administered intravenously over two minutes and recordings made for a further minimum of four minutes. In six patients, the direction of variceal flow was studied by means of a Doppler probe passed through the endoscope biopsy channel, immediately before variceal puncture and pressure measurement. ${ }^{\text {? }}$

Pentagastrin was chosen to constrict the LOS as it has (a) no effect on peristalsis in the body of the oesophagus, ${ }^{8}$ (b) a rapid onset of action on the LOS after intravenous administration, (c) a short duration of action, ${ }^{9}$ (d) no known effects on vascular tone. These pharmacodynamics facilitated a technically demanding study.

Each patient gave informed consent and the study was approved by the South Sheffield District Hospital Ethical Committee.

\section{CLINICAL TRIAL (CARRIED OUT IN CAIRO)}

All patients admitted to the emergency ward of Kasr El Aini Hospital with gastrointestinal bleeding were endoscoped between two and six hours after admission to ascertain the source of bleeding. Topical pharyngeal anaesthesia and light sedation (diazepam 5-15 mg) was used. No patient had received any specific treatment for suspected variceal bleeding such as vasopressin or balloon tamponade before endoscopy. Patients were included in the study if endoscopy showed active bleeding from the lowest $2 \mathrm{~cm}$ of oesophageal varices. The diagnosis of active variceal bleeding was made either if blood was seen to be spurting from a varix or fresh blood continually accumulated in the lower oesophagus which had not

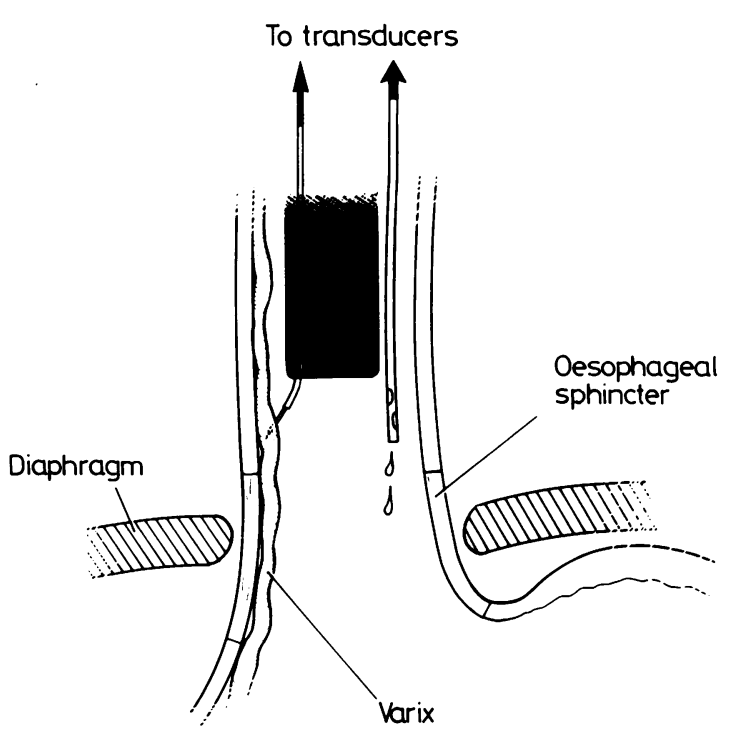

Fig. 1 Apparatus to record intravariceal and intraoesophageal pressures.

refluxed from the stomach. Patients who had undergone oesophageal surgery previously were excluded from the trial.

The endoscopist then left the room and the patient randomised, by means of instructions in a previously sealed envelope based on random numbers, to receive either $20 \mathrm{mg}$ metoclopramide intravenously or no injection. After 15 minutes, the patient was reendoscoped by the original endoscopist (who remained unaware of what treatment the patient had received), and recorded whether bleeding was still present or had stopped. An observation period of 15 minutes was chosen as this would allow sufficient time for the drug to effect haemostasis, but if it did not, then blood loss would not be excessive. All patients then received injection sclerotherapy and were managed according to the unit's policy of treating oesophageal varices. All endoscopies were performed by one of two endoscopists (SWH or WD).

Metoclopramide was used in preference to pentagastrin as it has a similar effect, but a much longer duration of action than pentagastrin on the LOS. When given as an intravenous bolus, it has an onset of action on the LOS between two and seven minutes later, which lasts for at least 60 minutes."

The trial was approved by the Kasr El Aini Hospital Ethical Committee.

\section{Results}

EXPERIMENTAL STUDY

At rest, the pressure gradient across the varix wall 
(intravariceal minus intraoesophageal pressure) varied between patients and was 12 to 36 (mean 23) $\mathrm{mmHg}$. Patients often coughed during the administration of pentagastrin making continuous readings difficult to obtain during this period. Because of this, completion of the pentagastrin injection was designated as the starting point of recording $(t=0$ minutes). Over the following one and a half to two

Table Comparison of patients who received metoclopramide and placebo

\begin{tabular}{lll}
\hline & Metoclopramide & Controls \\
\hline Patients (n) & 11 & 11 \\
Mean age & $41 \cdot 2$ ycars & $44 \cdot 5$ years \\
Child's grading A & 5 & 4 \\
$\quad$ B & 5 & 7 \\
C & 1 & 0 \\
Diagnosis & & \\
Bilharzial fibrosis & 3 & 4 \\
Posthepatitic cirrhosis & 2 & 1 \\
Chronic active hepatitis & 3 & 2 \\
Budd Chiari & 0 & 1 \\
Unknown & 3 & 4 \\
Previous sclerotherapy & 3 & 1 \\
BP <90 mmHg systolic & 2 & 0 \\
Size of varices Grade 1 & 0 & 6 \\
$\quad$ Grade 2 & 4 & 5 \\
\hline Grade 3 & 7 & 4 \\
\hline
\end{tabular}

Varices at the OGJ were graded as follows: with the oesophagus relaxed grade 1 were just visible, grade 2 protruded into the lumen by up to $50 \%$ of oesophageal radius and grade 3 filled the oesophageal radius.

minutes, intraoesophageal pressure remained relatively constant but intravariceal pressure fell in all but two patients to between 0 and $7($ mean $=4) \mathrm{mmHg}$ $(\mathrm{p}<0.001$, Student's $t$ test) (Fig. 2). After a further three minutes, the pressure gradient had risen again significantly $(p<0 \cdot 001)$. The fall in pressure gradient appeared to be directly related to the resting pressure $(\mathrm{r}=0.92, \mathrm{p}<0.001)$.

The two patients who showed minimal pressure reductions after receiving pentagastrin, of 6 and $4 \mathrm{mmHg}$, were found by Doppler to have caudad and bidirectional flow respectively (bidirectional is the term applied when flow is cephaled during inspiration and caudad in expiration). The remaining four patients assessed by Doppler had cephalad flow.

No patient experienced any complications as a result of the study.

CLINICAL TRIAL

Twenty two patients were randomised in the trial -11 to receive metoclopramide and 11 to the control arm.

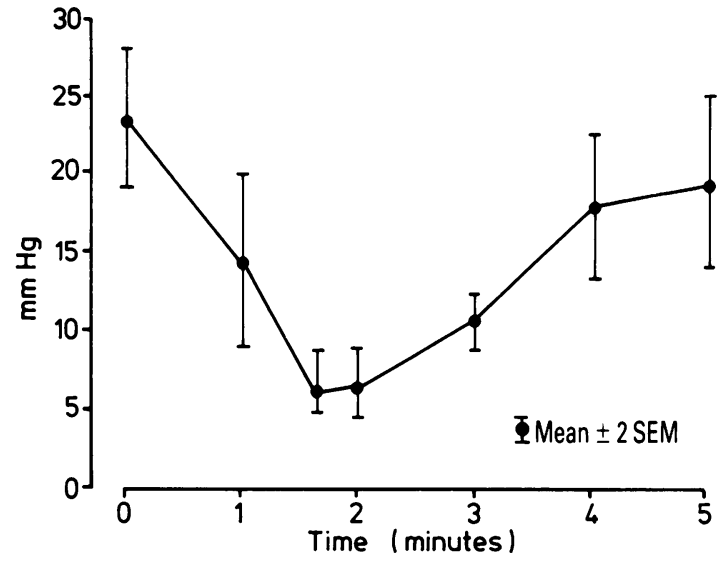

Fig. 2 Effect of pentastrin on variceal pressure gradient (intravariceal minus intraoesophageal pressure). Time 'zero' corresponds to completion of pentagastrin injection which was administered over two minutes.

This included all patients with active variceal bleeding and was approximately $25 \%$ of all the patients diagnosed to have bled from varices. No patient satisfying the entrance criteria for the trial was excluded.

The two groups were well matched for age, sex ratio, Child's grading, degree of shock, and size of varices (Table). The aetiology of each patient's portal hypertension was based on the history, and supported by a liver biopsy in five patients.

Of the 11 patients who received metoclopramide injection, 10 patients had stopped bleeding when reendoscoped 15 minutes after the initial endoscopy. One patient who had a spurting varix failed to stop bleeding after metoclopramide. In contrast, only four of the control patients had stopped bleeding but seven continued to bleed at the second endoscopy. Using $\chi^{2}$ analysis with Yates' correction this proved to be a significant difference $(\mathrm{p}<0 \cdot 01)$. Of the seven control patients who continued to bleed, sclerotherapy failed in two patients to arrest bleeding and a Sengstaken tube was required in both. In the other five patients, sclerotherapy was done with considerable difficulty but eventually controlled the bleeding.

\section{Discussion}

These results indicate that pharmacological constriction of the lower oesophageal sphincter is an effective alternative approach to the problem of actively bleeding oesophageal varices. Previous studies have shown the effect of LOS constriction on variceal blood flow to be considerable. Portographic studies indicate that LOS constrictors such as domperidone, metoclopramide, and pentagastrin all reduce or even 
abolish blood flow in submucosal oesophageal varices $^{56}$ whilst not affecting flow in paraoesophageal varices. These findings are supported further by studies of azygous blood flow, where Mastai et al" showed in patients with varices that the same drugs reduce azygous blood flow without altering cardiovascular haemodynamics. It was concluded that the effect was the result of their constricting action on the LOS and resultant reduction of submucosal variceal flow. The results obtained from these two forms of investigation are supported further by our own variceal pressures studies.

Intravenous pentagastrin has a maximal effect on the LOS after three minutes and after a further three minutes, LOS pressure returns to normal. ${ }^{9}$ In our experimental study, the effect of pentagastrin on variceal pressures were maximal between one and a half and two minutes after completion of the injection (which had been given over two minutes) and the effect had all but disappeared after a further three minutes. Further evidence for LOS constriction being responsible for the pressure changes is gained from the Doppler studies, where patients with cephalad flow showed a marked drop in intravariceal pressure measured just above the LOS, unlike those who had caudad or bidirectional flow. Even so, regardless of the direction of flow, we would still expect LOS constriction to compress varices within the LOS zone - that is, the area which is liable to bleed. Interestingly, Aronsen believed the haemostatic effect of vasopressin on bleeding oesophageal varices to be caused partly by the same mechanism based on portography and manometry in dogs. ${ }^{12}$ In patients given vasopressin, however, portography and manometry showed little or no effect on LOS pressure or variceal flow respectively. ${ }^{613}$

The evidence of others and our own experimental study suggested that pharmacological constriction of the LOS may be of sufficient force to compress varices so as to arrest active variceal bleeding; we therefore undertook our controlled trial. Current methods of arresting active variceal bleeding such as balloon tamponade, ${ }^{14}$ vasopressin with or without nitroglycerin, ${ }^{15}$ somastostatin, ${ }^{16}$ or emergency sclerotherapy, ${ }^{17}$ have limitations. These may be caused by lack of skilled nursing and medical personnel, side effects, cost of treatment, or lack of efficacy. Thus an effective, safe economic alternative is still required. The arrest of active variceal bleeding by metoclopramide appears to offer a genuine alternative to treatments already mentioned. This approach will, however, only be appropriate when bleeding originates from within the zone of the LOS. In patients with varices, the sphincter length is between 2 and $7 \mathrm{~cm}$ in $95 \%$ of patients ${ }^{18}$ and the squamocolumnar junction is between 0.9 and $2.1 \mathrm{~cm}$ from the lowest limit of the LOS. ${ }^{14}$ Therefore, in the majority of patients, pharmacological LOS constriction would be expected to affect variceal bleeding occurring from a zone extending from $1 \mathrm{~cm}$ below to $2 \mathrm{~cm}$ proximal to the squamocolumnar junction. In our experience and that of others ${ }^{3}$ most variceal bleeds occur from within this zone; nonetheless we would advocate endoscopy in every patient to confirm not only the site of bleeding but also that varices are the source of bleeding. In patients known to have varices, non-variceal bleeding occurs in over half. ${ }^{\prime}$

Whilst arrest of active bleeding on its own does not prolong survival ${ }^{14}$ (and must be followed by definitive treatment to prevent rebleeding), rapid and effective haemostasis will minimise the often inevitable hepatic decompensation that occurs in such patients. Metoclopramide is rather short acting" and longer acting drugs under evaluation such as cisapride $e^{21}$ may be of more use, particularly to non-specialist centres allowing stabilisation of the patient and safe transfer to another hospital, if required.

Mr S W Hosking was supported in Egypt by the Research Funds of Sheffield University and Special Trustees of the Former United Hospitals. Part of the material in this paper has appeared previously in abstract form in British Journal of Surgery, and Gut.

\section{References}

1 McCormack TT, Kennedy HJ, Salisbury J, Simms JM, Triger DR, Johnson AG. Bleeding in portal hypertension - implications of a sclerotherapy programme for medical and surgical care. Surg Gynecol Obstet 1985; 161: 557-62.

2 Terblanche J, Bornman PC, Kahn D, et al. Failure of repeated injection sclerotherapy to improve long term survival after oesophageal variceal bleeding. Lancet 1983; ii: 1328-32.

3 Paquet KJ. Endoscopic paravariceal injection sclerotherapy of the oesophagus - indications, techniques, complications: results of a period of 14 years. Gastrointest Endosc 1983; 29: 310-5.

4 Miskowiak J. How the lower oesophageal sphincter affects submucosal oesophageal varices. Lancet 1978; ii: 1284-5.

5 Miskowiak J, Burcharth F, Jensen L. Effect of lower oesophageal sphincter on oesophageal varices - a portographic study. Scand J Gastroentrol 1981; 16: 957-60.

6 Lunderquist A, Alwmark A, Gullstrand P, et al. Pharmacologic influence on esophageal varices: a preliminary report. Cardiovasc Intervent Radiol 1983; 6: 65-71.

7 McCormack TT, Smallwood RH, Walton L, Martin T, Robinson P, Johnson AG. Doppler ultrasound probe for assessment of blood flow in oesophageal varices. Lancet 1983; i: 677-8.

8 Hollis JB, Levine SM, Castell DO. Differential sensi- 
tivity of the human esophagus to pentagastrin. Am J Physiol 1972; 222: 870-4.

9 Behar J, Biancani P. Effect of cholecystokininoctapeptide on lower esophageal sphincter. Gastroenterology 1977; 73: 57-61.

10 Guelrud M. Effect of intravenous metoclopramide on the incompetent lower esophageal sphincter. Am J Gastroenterol 1974; 61: 119-24.

11 Mastai R, Grande L, Bosch J, et al. Effects of metoclopramide and domperidone on azygos venous blood flow in patients with cirrhosis and portal hypertension. Hepatology 1986; 6: 1244-7.

12 Aronsen KF, Nylander G. The mechanism of vasopressin haemostosis in bleeding oesophageal varices. Acta Chir Scand 1966; 131: 433-53.

13 Boesby S, Pedersen SA. The effect of vasopressin on resting gastroesophageal sphincter pressure in man. Scand J Gastroenterol 1974; 9: 587-90.

14 Hunt PS, Korman MG, Hansky J, Parkin WG. An 8year prospective experience with balloon tamponade in emergency control of bleeding esophageal varices. Dig Dis Sci 1982; 27: 413-6.

15 Gimson AES, Westaby D, Hegarty J, Watson A,
Williams R. A randomised trial of vasopressin and vasopressin plus nitroglycerin in the control of acute variceal haemorrhage. Hepatology 1986; 6: 410-3.

16 Jenkins SA, Baxter JN, Corbett W, Devitt P, Ware P, Shields R. A prospective randomised controlled clinical trial comparing somatostatin and vasopressin in controlling acute variceal haemorrhage. Br Med J 1985; 290: 275-8.

17 Johnson AG, Simms JM, Stoddard CJ. Is there a role for injection sclerotherapy in the presence of active bleeding? In: Westaby D, MacDougall BRD, Williams R, eds. Variceal bleeding. London: Pitman Books, 1982: 159-64.

18 Murray-Lyon IM, Ogle SJ, Johnson AG. Changes in oesophageal function after injection sclerotherapy. In: Westaby D, MacDougall BRD, Williams R, eds. Variceal bleeding. London: Pitman, 1982: 176-83.

19 Liebermann-Meffert D, Allgower M, Schmid D, Blum AL. Muscular equivalent of the lower esophageal sphincter. Gastroenterology 1979; 76: 31-8.

20 Wienbeck M, Cuder-Wiesinger E, Berges W. Comparative study of cisapride's versus metoclopramide's effect on esophageal motility. Digestion 1986; 34: 141-2. 